\title{
The Effects of an Implemental Mind-Set on Attitude Strength
}

\author{
Marlone D. Henderson \\ University of Chicago
}

\author{
Yaël de Liver \\ Utrecht University
}

\author{
Peter M. Gollwitzer \\ New York University and University of Konstanz
}

\begin{abstract}
The authors investigated whether an implemental mind-set fosters stronger attitudes. Participants who made a decision about how to act (vs. those who held off) expressed a more extreme attitude toward an issue unrelated to the decision (Experiment 1). Participants who planned the implementation of a decision (vs. deliberated vs. control) exhibited less ambivalent (Experiment 2) and more accessible (Experiment 3 ) attitudes toward various objects unrelated to the decision. Moreover, an attitude reported by planning participants better predicted self-reported behavior 1 week later (Experiment 4). Finally, results suggest that the effect of an implemental mind-set on attitude strength toward unrelated objects is driven by a focus on information that supports an already-made decision (Experiment 5). Implications for attitudes, goals, and mind-sets are discussed.
\end{abstract}

Keywords: extremity, ambivalence, accessibility, mind-set, attitude strength

Although daily life is filled with examples of people expressing their strong attitudes in social settings (e.g., pro-choice protesters, religious fundamentalists), it is clear that people also frequently evaluate attitude objects that elicit weak reactions as well. These weak reactions include, for example, attitudes that are rife with contradictory feelings and beliefs, attitudes that are moderate rather than extreme, and attitudes that are expressed with some hesitancy or slowness. Strong and weak attitudes can be functional, depending on the current action control problem at hand (Gollwitzer, 1990; Kuhl, 1985). For example, although high levels of ambivalence may indicate appropriate caution when deciding whether to pursue alternative end states, they may also be indicative of counterproductive behavior (second-guessing and indecisiveness) during actual goal striving (Armor \& Taylor, 2003;

Marlone D. Henderson, Department of Psychology, University of Chicago; Yaël de Liver, Department of Social and Organizational Psychology, Utrecht University, Utrecht, the Netherlands; Peter M. Gollwitzer, Department of Psychology, New York University, and Department of Psychology, University of Konstanz, Konstanz, Germany.

This research was supported by a grant from the Interdisciplinary Center for Research on Intentions and Intentionality at the University of Konstanz to Peter M. Gollwitzer and grants from the Netherlands Organization for Scientific Research and Netherlands Organization for Health Research and Development to Yaël de Liver.

Many thanks to Gliana Ramirez, Anastasia Adler, and Ryan D. Coganow for their assistance with data collection and to Amie Green, Masumi Iida, and Joshua Correll for their assistance with data analyses. Special thanks also go to Kentaro Fujita for extensive discussion of ideas and to Penny Visser and Zakary L. Tormala for comments on a draft of this article.

Correspondence concerning this article should be addressed to Marlone D. Henderson, Department of Psychology, University of Chicago, 5848 South University Avenue, Chicago, IL 60637. E-mail: mhenderson@uchciago.edu
Brandstätter \& Frank, 2002; Higgins, Kruglanski, \& Pierro, 2003; Kruglanski et al., 2000). Therefore, attitude as well as action control (goal) researchers have recognized the importance of identifying factors that strengthen and weaken evaluative reactions. The current set of studies examined the proposition that a mind-set related to action control (i.e., the implemental mind-set originating from planning the implementation of a chosen goal) can affect attitude strength toward objects that are unrelated to that action.

\section{Attitude Strength}

The impact of an attitude on individuals' responses toward objects depends on two properties of the attitude constructcontent and strength. Content refers to the overall evaluation (positive or negative) of some attitude object. Strength refers to the overall evaluation's persistence over time, influence on cognitive processing, resistance to change, and regulation of behavior (Krosnick \& Petty, 1995). Whereas the content of the attitude determines the direction of the impact, the strength of the attitude determines the degree to which the attitude steers people's reactions. Several indicators or aspects of strong attitudes have been especially well studied (see Petty \& Krosnick, 1995, for a review), including accessibility (e.g., Fazio, Chen, McDonel, \& Sherman, 1982), certainty (e.g., Tormala \& Petty, 2002), importance (e.g., Krosnick, 1988), extremity (e.g., Downing, Judd, \& Brauer, 1992), and ambivalence (e.g., Visser \& Mirabile, 2004). Although some researchers have argued that one or two higher order constructs can capture these properties of attitude strength (e.g., Bassili, 1996; Pomerantz, Chaiken, \& Tordesillas, 1995), others have called for a more complex framework (e.g., Krosnick, Boninger, Chuang, Berent, \& Carnot, 1993; Raden, 1985; Visser, Bizer, \& Krosnick, 2006; Visser, Krosnick, \& Simmons, 2003).

Notably, Pomerantz and her colleagues (Pomerantz et al., 1995; Tordesillas, Pomerantz, Chaiken, \& Zimmerman, 1994, as cited in Pomerantz et al., 1995, p. 416) investigated how certain aspects of 
attitude strength produce selective judgments through different forms of biased cognitive processing. They conceptualized selective judgments as a form of resistance against attitude change and examined the impact such resistance had on attitude and behavior relations. Pomerantz and her colleagues found that particular aspects of attitude strength (certainty, extremity, ambivalence, accessibility) that center on how confident individuals are in their attitudes loaded onto what they called a Commitment factor. They found that increases in such properties were associated with a "closed-minded orientation" (Pomerantz et al., 2005, p. 415) toward attitude-incongruent information. These findings suggest that if individuals can be guided to spontaneously adopt an evaluatively closed-minded orientation, they should exhibit increased strength in their attitudes.

\section{Action Phases and Mind-Sets}

Over the last 20 years, research has shown that thinking about an object (e.g., vacation) in the context of a plan (e.g., How will I plan my vacation?) versus a deliberative choice (e.g., Should I go on a vacation or not?) can influence how people handle available information (for reviews, see Gollwitzer, 1990; Gollwitzer \& Bayer, 1999; Gollwitzer, Fujita, \& Oettingen, 2004). These findings have been interpreted in terms of mind-set theory (Gollwitzer, 1990), which postulates that the unique tasks associated with the different action phases of goal pursuit lead to the activation of appropriate cognitive procedures or mind-sets. For instance, when individuals are in a postdecisional or planning phase of goal pursuit, they face the task of promoting the initiation of action that is instrumental to attaining the chosen goal. Solving this task requires individuals to remain committed to their goal decision, because implemental concerns will fail if individuals begin to doubt themselves (Armor $\&$ Taylor, 2003). Therefore, individuals in a planning mode often engage in a selective, one-sided analysis of information that supports their dominant (favorable) evaluation of goal-relevant issues (Gagné \& Lydon, 2001a; Harmon-Jones \& Harmon-Jones, 2002; Puca, 2001; Taylor \& Gollwitzer, 1995). Or when individuals are in a predecisional or deliberative phase of goal pursuit, they have the task of making the best possible choice of which end-state to pursue in the first place. Because it is unclear when choosing between alternative end-states which pieces of information might be relevant to assessing the desirability and feasibility of a particular end-state, individuals are likely to remain even-handed and unbiased when processing incoming or stored information. This open-minded orientation occurs regardless of whether it supports or contradicts the individual's dominant attitude toward potential goal-relevant issues (Puca, 2001; Taylor \& Gollwitzer, 1995; also see Gerard, 1967).

The task that a person engages in activates cognitive procedures that are relevant to solving the specific task at hand (i.e., planning or deliberating), which can then extend to other unrelated objects (see Gollwitzer et al., 2004, for a review). The sum total of the activated cognitive procedures is dubbed mind-set (Bargh \& Chartrand, 2000; Heckhausen \& Gollwitzer, 1987; also see Smith $\&$ Branscombe, 1987). Studies from as early as the 1900s described how encountering tasks that require the use of a particular procedure, such as attending to the frequency of a particular stimulus, increases the likelihood that the procedure will be used on subsequently encountered tasks (Ach, 1910; Külpe, 1904; Rees
\& Israel, 1935). More recent work has continued to show that mind-sets can be used as a framework for explaining cognitive carryover effects in various social psychological domains outside of goal pursuit (e.g., Chen, Shechter, \& Chaiken, 1996; Galinsky \& Moskowitz, 2000; Hugenberg, Bodenhausen, \& McLain, 2006; Kray, Galinsky, \& Wong, 2006; Sassenberg \& Moskowitz, 2005; Sassenberg, Moskowitz, Jacoby, \& Hansen, 2007).

As an illustration of the mind-set work that has been done in the domain of goal pursuit, we cite a study that found when testing participants' memory concerning an unrelated task that participants who were asked to plan the implementation of a decision recognized incidental information that was peripherally displayed less often than participants who were in a predecisional, deliberative state (Gollwitzer, Bayer, \& Wasel, 1998, as cited in Gollwitzer \& Bayer, 1999, p. 408; see also Fujita, Gollwitzer, \& Oettingen, 2007). Such differences in selective attention are thought to be especially indicative of an implemental mind-set because goal implementation is likely to be more successful as people narrow their focus to avoid potentially distracting stimuli. Of importance, the motivational consequences that result from this one-sided focus have also been shown to transfer to newly encountered stimuli. For example, Taylor and Gollwitzer (1995) showed that implemental mind-set participants who planned how to achieve an already decided end-state viewed themselves as less vulnerable to experiencing an unrelated risky event than deliberative-mind-set participants who considered whether to pursue an end-state in the first place. Although such findings do not speak directly to the impact of an implemental mind-set on attitude strength, they are consistent with the notion that overall confidence differs between action phases of goal pursuit.

\section{Implemental Mind-Set and Attitude Strength}

In the present studies, we aimed to bring the concept of mind-set to bear on attitudes. One finding that is clear from research both inside and outside the tradition of mind-set theory (Gollwitzer, 1990 ) is that individuals who commit to a certain course of action tend to engage in an unambiguous, evaluatively polarized or onesided assessment of information in support of their dominant attitude (Brandstätter \& Frank, 2002; Brehm, 1956; Frey, 1986; Wicklund \& Brehm, 1976), regardless of whether that attitude is positive or negative (Bayer \& Gollwitzer, 2005). This one-sided assessment fosters the transition of the made decision into actual action and goal attainment. In terms of attitude theory, one could say that the attitude toward the goal becomes stronger. Indeed, a pilot study confirmed that participants who were asked to think about the steps that were needed to implement a made decision rather than the pros and cons for making a decision a particular way later reported stronger (less ambivalent) attitudes about the topic of that decision (de Liver, Henderson, \& Gollwitzer, 2003). Given the carryover properties of mind-sets, we hypothesized that as people moved into the implemental, planning phase of goal pursuit, they would also experience an increase in attitude strength toward objects that are unrelated to their current goal pursuit. The current set of experiments tested this hypothesis with respect to a variety of attitude objects.

In Experiment 1, we tested whether implemental mind-set participants were more likely than deliberative mind-set participants to adopt an extreme position toward an issue that is irrelevant to 
their goal concern. In Experiment 2, we tested whether implemental mind-set participants evidenced lower levels of ambivalence than did deliberative and neutral mind-set participants toward a variety of unrelated objects. In Experiment 3, we tested whether implemental mind-set participants evidenced more accessible evaluations of unrelated objects than did deliberative and neutral mind-set participants. In Experiment 4, we tested whether implemental mind-set participants evidenced a greater correspondence between their attitude and behavior for an unrelated issue than did neutral mind-set participants. In Experiment 5, we investigated the process that is hypothesized to underlie the effects of an implemental mind-set on attitude strength. Specifically, we tested whether implemental mind-set participants directed to focus on the pros behind their decision evidenced a stronger attitude toward an unrelated issue than did implemental mind-set participants directed to focus on both the pros and cons behind their decision.

\section{Experiment 1: Does an Implemental Mind-Set Increase Attitude Extremity?}

In an implementation phase of goal pursuit, the task is to plan action and avoid the consideration of information that might interfere with carrying out a decision. An evaluatively two-sided perspective has the potential to obstruct the task of implementation because it gives conflicting behavioral cues. One way to avoid such conflict is to selectively process information about objects in a positive or negative direction (Nordgren, van Harreveld, \& Van der Pligt, 2006). As an implemental mind-set is posited to transfer a general increase in attitude strength via selective information processing, this study assessed attitudinal extremity with an open-ended measure. Thought-listing is a key tool for assessing the degree of information processing (Cacioppo, von Hippel, \& Ernst, 1997; Heckhausen \& Gollwitzer, 1987). In the current experiment, we tested whether an implemental versus deliberative mind-set leads to a more extreme (evaluatively one-sided) position toward a controversial issue.

\section{Method}

\section{Participants}

Participants were 36 students ( 23 women, 13 men) enrolled in one of several psychology courses, who participated in partial fulfillment of a course requirement. The mean age for participants in this experiment and all remaining experiments was 19 years old. No gender or age differences emerged for any of the analyses reported. The sample for this experiment and all remaining experiments was restricted to participants who had never participated in any mind-set experiments.

\section{Procedure and Materials}

Participants were randomly assigned to a deliberative or implemental mind-set group, with 18 participants in each condition. We invited participants to a lab experiment dealing with the assessment of students' perspective toward different objects. Participants were ushered into separate experimental cubicles, with each cubicle equipped with a computer. Participants were informed that they would be engaging in two separate tasks during the course of the experiment. As a cover story, participants in all conditions were told that as a measure of relationship sensitivity, they would have the opportunity to write as though they were giving advice to others about how they should handle relationship problems. For this task, they would have a choice between two topics to write about (i.e., sexual inexperience and honesty issues in romantic relationships). The crucial difference was that depending on condition, participants were either asked to make this choice before (implemental mind-set) or after (deliberative mind-set) engaging in the second task.

In the second task, which constituted the measure of interest, participants first read information about a controversial issue. After that, they wrote down their thoughts about this issue, and we calculated whether participants' thoughts about this unrelated issue were evaluatively one- versus two-sided. Note that while responding to the second task (attitude measure), participants in the deliberative mind-set condition expected to go back to the first task (romantic relationship advice) and receive more information in order to make their decision. Participants in the implemental mind-set condition, on the other hand, expected to go back to the first task and begin working on it (writing advice). In essence, participants in the deliberative mind-set condition were interrupted in the midst of making their decision, whereas participants in the implemental mind-set condition were interrupted in the midst of preparing to carry out their decision.

Mind-set manipulation. We created a deliberative and implemental mind-set with the choice paradigm used in previous mindset research (e.g., Armor \& Taylor, 2003; Fujita et al., 2007; Heckhausen \& Gollwitzer, 1987; Puca \& Schmalt, 2001). Participants were asked to pick for themselves the relationship area (sexual inexperience or honesty) on which they felt more capable of giving advice. Participants in the deliberative mind-set condition were told that the best way to find out which type of relationship area that they were better equipped to give advice on was to read letters that represented both areas. Participants were then led to believe that they would read one sample letter from each of the two problem areas in order to help them decide which area would allow them to give their best advice. Participants were then told that after they read both sample letters, they would choose the area on which they wanted to give advice. It was stressed to participants that they should hold off making their decision until they read both sample letters. Participants were then asked to indicate to the experimenter which sample letter (sexual inexperience or honesty) that they wanted to read first.

Participants in the implemental mind-set condition were asked to choose the relationship area on which they wanted to give advice. Participants were told that if they considered themselves to be a person who gave better advice on issues related to either sexual inexperience or honesty in relationships, then they should choose that particular area on which to give advice. In contrast to deliberative mind-set participants, implemental mind-set participants were not told that they would receive any sample letters in order to aid in their decision making. Rather, implemental mindset participants were told that they would receive a sample letter after they had made their decision in order to help them prepare for giving advice to others.

We controlled for exposure to different information between our experimental conditions by having all participants read only one letter. Deliberative mind-set participants who chose to receive the sexual inexperience (honesty) letter first and implemental mind-set 
participants who chose to give advice on the sexual inexperience (honesty) area received a letter titled "Sample Sexual Experience Issue Letter" ("Sample Honesty Issue Letter"). The content of the letter was the same, regardless of participants' choice (see Appen$\operatorname{dix}$ A). The letter contained elements of dishonesty and sexual inexperience, so it was believable that it represented the type of honesty or sexual inexperience issues for which people might ask for advice. ${ }^{1}$

Dependent measure. After reading the sample letter, participants were interrupted to do the second task, which was completing an attitude measure on an unrelated topic. All instructions for this task were given on the computer. As an introduction to this attitude questionnaire, participants were asked to provide their opinion on a topic that was supposedly being debated within the United States-whether the government should be allowed to read foreigners' e-mail. ${ }^{2}$ Specifically, participants read the following:

We are interested in getting your position on an issue that is being hotly debated within United States right now. How much access should the government (e.g., CIA, FBI) have to foreigners' e-mail? On the one hand, Americans believe that foreigners should be able to communicate without worrying about whether other people are spying on them and learning things about them that might be used to damage their reputation, career, or relationships. On the other hand, Americans want this kind of oversight because it helps protect the country from individuals and organizations that only want to hurt the country economically, physically, and emotionally.

In order to reduce the likelihood that participants already held a strong attitude toward this issue, we restricted our sample to participants who were not foreigners. Participants were also told that their responses would be completely anonymous.

Participants were asked to provide an open-ended response regarding their thoughts on the issue. We had two independent raters (both blind to condition) code how polarized each participant's position was toward the issue using the following system: Individuals who stated they were completely against the government allowing the reading of foreigners' e-mail received a code of -1 . Individuals who stated they were against the government allowing the reading or foreigners' e-mail but also mentioned exceptions in which they would be in favor of it or mentioned the possibility of it being done in a way that they would favor received a code of 0 . Individuals who stated they were in favor of the government allowing the reading of foreigners' e-mail but also mentioned exceptions in which they would not be in favor of it or mentioned the possibility of it being done in a way that they would not favor also received a code of 0 . Finally, individuals who stated they were completely in favor of the government allowing the reading of foreigners' e-mail received a code of 1 (see Appendix $\mathrm{B}$ for examples of each coded response).

Agreement among raters was high $(r=.89)$. Disagreements were resolved through discussion. Using the coding system, we created an index of whether participants expressed an evaluatively one-sided or two-sided attitude toward the issue. Specifically, we examined the number of participants in each condition who received a code of -1 or 1 and compared it with the number of participants who received a code of 0 . This served as our main dependent variable. After responding to the open-ended question, participants answered demographic questions. Before proceeding back to the relationship task, participants were asked to recall the sample letter. After this memory check, participants were thoroughly debriefed and thanked.

\section{Results}

\section{Attitude Extremity}

We analyzed the proportion of participants who adopted an evaluatively one-sided position toward the focal issue using logistic regression, with the deliberative mind-set condition coded as 0 and the implemental mind-set condition coded as 1 . As expected, we found a significant effect of condition $(B=1.41$, odds ratio $=$ 4.09 , Wald $=3.88, p<.05$ ). When we examined the type of attitude expressed by the 18 participants in the deliberative mindset condition, the following pattern emerged: 4 (22.2\%) expressed a completely negative attitude, $11(61.1 \%)$ expressed a moderate attitude, and $3(16.7 \%)$ expressed a completely positive attitude. When we examined the type of attitude expressed by the 18 participants in the implemental mind-set condition, the following pattern emerged: $10(55.6 \%)$ expressed a completely negative attitude, $5(27.8 \%)$ expressed a moderate attitude, and $3(16.7 \%)$ expressed a completely positive attitude. Overall, $72.2 \%$ of participants in the implemental mind-set condition expressed an evaluatively one-sided position toward the focal issue, whereas only $38.9 \%$ of participants in the deliberative mind-set did so.

\section{Equivalency of the Groups}

In order to check whether our experimental groups engaged in different amounts of effortful processing prior to the attitude assessment, we analyzed participants' memory of the sample letter. We created two memory indices, with the second being more stringent than the first. The first index was based on the extent to which participants recalled the gist or overall purpose of the letter. Specifically, we analyzed whether participants recalled that the author of the letter was involved in an online relationship and was unsure about how to develop the relationship, given that the other person was more attractive. All participants recalled the gist of the letter. The second index was based on the extent to which participants recalled the exact details of the letter. Overall, there were 25 pieces of information conveyed in the letter (see Appendix A). For example, the first sentence in the letter contained the following four pieces of information: (a) "I met this person on the Internet" (b) "three months ago" (c) "and we talk everyday," and (d) "through instant messenger." Results revealed no difference between the deliberative $(M=8.06, S D=2.98)$ and implemental $(M=8.50, S D=4.63)$ mind-set groups in the amount of infor-

\footnotetext{
${ }^{1}$ Results revealed that the implemental and deliberative mind-set groups did not significantly differ in the extent to which they believed they were reading about a particular content area in their sample letter. Specifically, $50 \%$ of participants in the implemental mind-set group choose the honesty area to give advice on and expected to receive a sample letter from that supposed area, and $67 \%$ of participants in the deliberative mind-set group choose to receive their first sample letter from the honesty area, $X^{2}$ $(1,36)=1.03, p=.31$

${ }^{2}$ Note that at the time that this experiment was conducted, it was not publicly known that the United States' National Security Agency was monitoring domestic and international communications.
} 
mation recalled $(t<1)$. We also examined whether participants in the experimental groups engaged in different amounts of effortful processing during the attitude assessment by analyzing the number of words that were used in their open-ended responses. Results revealed that the deliberative $(M=54.11, S D=33.21)$ and implemental $(M=54.56, S D=36.19)$ mind-set groups did not differ in the length of their evaluative responses $(t<1)$. Indeed, the extremity of position results remained the same after controlling for the length of participants evaluative responses. Therefore, these results can not be explained in terms of differences in verbosity between our experimental groups. ${ }^{3}$

\section{Discussion}

Implemental mind-set participants were almost twice as likely as deliberative mind-set participants to adopt an evaluatively onesided position toward an issue that was completely unrelated to the goal decision at hand. The extent to which individuals adopt a one-sided or unqualified position toward an issue is assumed to be one of the most obvious indicators of attitude extremity (Abelson, 1995). Because both groups were exposed to the same information and no differences were found in the recall of stimulus information or length of evaluative responses, it seems unlikely that the observed differences in extremity can be explained by differences in information exposure or effortful processing between the groups. Rather, it seems that it was the differences between the phases of goal pursuit that participants were engaged in that led them to adopt an evaluatively one-sided (closed-minded) reaction toward an unrelated controversial issue.

In the next experiment, we extended our examination of the effects of mind-sets on attitude strength in several ways. First, we examined a different property of attitude strength, namely attitudinal ambivalence. Second, we activated a deliberative and implemental mind-set using a different paradigm. Third, we included a control group in the design because one potential criticism of Experiment 1 is that our observed differences in attitude strength were due to the fact that we explicitly told our deliberative mindset group to hold off on making a judgment. By including a control group in the remaining studies, we can clarify the interpretation of our results. Finally, we tested the generality of the effects of mind-sets by assessing ambivalence toward a variety of objects, thus testing the assumption even more critically that an implemental mind-set increases the strength of attitudes toward irrelevant objects and issues.

\section{Experiment 2: Does an Implemental Mind-Set Decrease Attitude Ambivalence?}

In this experiment, participants were asked to report their subjective experience of ambivalence toward numerous objects. Prior to giving their evaluations, participants were induced into a deliberative, implemental, or a neutral mind-set. By adding the neutral mind-set control group, we can test whether any change in ambivalence that is observed is due to the implemental mind-set, deliberative mind-set, or both. Admittedly, it is difficult to make exact predictions about the outcome of each mind-set on ambivalence relative to a "neutral mind-set," mainly because it is unclear whether such a neutral mind-set can be successfully created (see Armor \& Taylor, 2003, p. 89; Taylor \& Gollwitzer, 1995, p. 217 , for similar discussions; also see Campbell \& Stanley, 1963, p. 13). That is, even if a control group of individuals in a neutral mind-set were not given any instruction to adopt a deliberative or implemental mind-set, they might still spontaneously adopt a particular mind-set during the course of an experiment. Indeed, one possibility is that individuals in a neutral mind-set control group might be so focused on planning their next task in the experiment that they might exhibit no differences in ambivalence relative to individuals in an implemental mind-set but still exhibit reduced levels of ambivalence compared with individuals in a deliberative mindset. Another possibility is that because individuals in neither a neutral nor a deliberative mind-set group are required to come to a decision on a particular end-state, both groups might exhibit similar levels of ambivalence while still exhibiting elevated levels compared with individuals in an implemental mind-set.

\section{Method}

\section{Participants}

Participants were 123 students (99 women, 24 men) enrolled in an introductory psychology course, who participated in partial fulfillment of a course requirement. We invited participants to take part in an e-mail study that involved getting students' perspective on several objects. All participants who signed up then received an e-mail with a computer program as an attachment that included the study materials. Participants were told that they would be taking part in separate tasks that dealt with getting their perspective on things, with one task focused on how students think about personal problems and projects and the other task focused on the attitudes that students have toward things. Participants were randomly assigned to one of three conditions: deliberative, implemental, or neutral mind-set control group. There were 41 participants in each condition.

\section{Procedure and Materials}

Participants assigned to the mind-set conditions were first induced into either a deliberative or an implemental mind-set for the first task and then had their ambivalence assessed toward a variety of objects for the second task. Participants assigned to the neutral mind-set condition responded to our dependent measure of ambivalence without being induced into a particular mind-set beforehand (see Gagné \& Lydon, 2001a, 2001b; Gollwitzer \& Kinney, 1989). Participants in our neutral mind-set condition were induced into a mind-set after reporting their attitude in order to be able to use the same cover story (i.e., "take part in two tasks") for all participants.

Mind-set manipulation. In this experiment, we created a deliberative and implemental mind-set by employing the personal problem versus project paradigm used in previous mind-set re-

\footnotetext{
${ }^{3}$ Political ideology was measured during a separate mass questionnaire session by means of the following item: "We hear a lot of talk these days about liberals and conservatives. Where on the following scale of political orientation would you place yourself?" The answer scale ranged from -5 (extremely liberal) to 5 (extremely conservative). We found no difference between groups $(t<1)$, with the average political orientation of the deliberative $(M=-2.39)$ and implemental $(M=-1.69)$ mind-set groups falling on the liberal side. We thank John T. Jost for providing this data set.
} 
search (e.g., Gollwitzer, Heckhausen, \& Steller, 1990; Gollwitzer \& Kinney, 1989; Taylor \& Gollwitzer, 1995). Specifically, we activated a deliberative mind-set by asking participants to nominate a personal problem in their life and weigh the pros and cons of making or not making a personal change decision regarding that problem (e.g., "Should I move out of the dormitory?"). Participants listed both the potential positive and negative, short-term and long-term consequences of deciding one way or another on the problem they nominated. In contrast, we activated an implemental mind-set by asking participants to nominate a personal project in their life and plan the implementation of that project. Participants named a project that they intended to accomplish within the following 3 months (e.g., to move out of the dormitory) and then listed the five most crucial steps that they deemed necessary to implementing that project. After which, they indicated when, where, and how they wanted to perform those steps.

Dependent measure. We generated a list of 30 objects for this experiment (see Appendix C). Participants were simply asked to report how ambivalent they were toward each object. Specifically, we measured participants' ambivalence by asking "How conflicted/ambivalent are your feelings and/or beliefs towards. ..." Answers were given on a 6-point scale that ranged from 1 (not at all ambivalent) to 6 (extremely ambivalent). The order of each object was randomly determined for each participant. Given that we were specifically interested in assessing participants' general experience of ambivalence across different objects, we created a measure of ambivalence by averaging participants' responses to the 30 items ( $\alpha=.85$; see de Liver, Van der Pligt, \& Wigboldus, 2007).

After participants completed the computer program, an electronic file of their responses was e-mailed to the experimenter. They were then thanked and fully debriefed.

\section{Results}

\section{Content of Manipulation}

Adopting the coding system used in previous research (e.g., Gollwitzer, Heckhausen, \& Steller, 1990), we found that $50.0 \%$ of participants' problems and projects dealt with career-related issues (e.g., becoming a lawyer, deciding whether to work during a year off from school), $22.0 \%$ dealt with lifestyle-related related issues (e.g., becoming more healthy, deciding whether to get help with mood problems), and $28.0 \%$ dealt with interpersonal issues (e.g., breaking up with boyfriend, deciding whether to move in with sibling).

\section{Attitude Ambivalence}

In order to ensure that our results were not due to any semantic relationship between the objects and participants' goal decisions, we took the following steps before analyzing ambivalence ratings. We identified all objects that were semantically related to the topic that participants had chosen in the manipulation phase $(.04 \%$ versus $.03 \%$ for deliberative and implemental mind-set conditions, respectively). We then deleted participants' rating for these specific objects before creating an index of ambivalence. For example, 1 participant's problem in the deliberative mind-set group dealt with "whether to continue as a pre-health major," which led us to delete that participant's rating for "nurses." In another case,
1 participant's project in the implemental mind-set group dealt with "how to get into medical school," which led us to delete that participant's ratings for "nurses." Finally, for each participant we calculated the mean ambivalence score across the objects.

Participants' ambivalence score was entered into a one-way analysis of variance (ANOVA), with mind-set condition (implemental, deliberative, and neutral) as a between-participant variable. The condition effect was significant, $F(2,120)=3.35, p<$ .05. Specific comparisons revealed that the implemental mind-set group evidenced a significantly lower amount of ambivalence $(M$ $=2.46, S D=0.55)$ compared with the deliberative $(M=2.74$, $S D=0.67), t(80)=2.02, p<.05, d=0.45$, and neutral $(M=$ 2.80, $S D=0.66), t(80)=2.52, p<.05, d=0.56$, mind-set groups. No significant difference was observed between the deliberative and neutral mind-set groups $(t<1)$.

\section{Discussion}

Consistent with our conceptual framework, results showed that compared with the neutral and deliberative mind-set groups, the implemental mind-set group expressed the lowest amount of ambivalence toward a variety of objects. The objects that we asked participants to evaluate were taken from all domains of life (i.e., health, leisure, business, and food), and consistent results were obtained even after we restricted our analyses to objects that were not related to participants' listed problems and projects. Accordingly, the observed implemental mind-set effect cannot be explained as a consequence of semantic priming (see Bargh \& Chartrand, 2000, for a similar discussion) but rather should to be interpreted in terms of procedural (or mind-set) priming.

Regarding the direction of our observed effect, we failed to find any difference between our deliberative and neutral mind-set conditions on attitudinal ambivalence, suggesting that our results are not due to any demand conveyed in the instructions for activating a deliberative mind-set. It is important to reiterate that the deliberative mind-set is centered on the predecisional phase of goal pursuit where people have to solve the task of choosing between wishes (i.e., potential goals). As becoming involved with this task activates a cognitive procedure that leads to open-mindedness (Fujita et al., 2007), our lack of difference between the neutral and deliberative mind-set conditions might suggest that participants in a relatively benign experimental context naturally gravitate or default toward an open-minded state until they set upon the task of concerning themselves with how to carry out an already set goal, a possibility that we consider later (see the General Discussion section).

\section{Experiment 3: Does an Implemental Mind-Set Increase Attitude Accessibility?}

In this experiment, we tested whether individuals induced into an implemental mind-set evidence more accessible attitudes (faster evaluative response latencies) than individuals not induced into an implemental mind-set. Attitude accessibility, usually measured by response latencies to overall evaluations, is an important operative index of attitude strength, as it refers to the strength of the link between the attitude object and an overall evaluation. Interestingly, previous research has shown that individuals slow down when evaluating objects that elicit higher amounts of ambivalence (e.g., 
Bargh, Chaiken, Govender, \& Pratto, 1992; Brömer, 1998; Huckfeldt \& Sprague, 2000). Consequently, we decided to also test whether individuals induced into an implemental mind-set would show the greatest advantage in terms of their speed-up effect for objects that have the potential to elicit high amounts of ambivalence. In other words, we examined whether the type of self-regulatory mind-set that is activated interacts with the type of object that is evaluated (high ambivalence vs. low ambivalence) in determining how fast participants report their evaluations.

\section{Method}

\section{Participants}

Participants were 96 students ( 78 women, 18 men) enrolled in one of several psychology courses who participated in partial fulfillment of a course requirement. The design of the current study was a 3 (mind-set condition: deliberative vs. implemental vs. neutral) $\times 2$ (potential attitudinal ambivalence elicited by object: low vs. high) $\times 2$ (evaluation: good vs. bad), with the first variable as a between-participant variable and the last two variables as within-participant variables. There were 32 participants in each condition.

\section{Procedure}

We invited participants to a lab experiment dealing with the assessment of students' perspective toward several objects. Participants were ushered into separate experimental cubicles, each of which was equipped with a computer. All participants were informed that they would be engaging in two separate tasks during the course of the experiment. For the first part participants were induced into their respective mind-set, and for the second part they reported their summary evaluation of a variety of objects. As in Experiment 2, all materials were presented on a computer.

Mind-set manipulation. Disguised as a personality assessment tool (see Harmon-Jones \& Harmon-Jones, 2002), the same procedure as in Experiment 2 was used to activate a deliberative and implemental mind-set. For the neutral mind-set control condition, participants were asked to think about an ordinary day in their life and asked to describe at least seven things that they normally do during a typical day (see Harmon-Jones \& Harmon-Jones, 2002).

Dependent measure. To measure attitude accessibility, we used the procedure outlined by Fazio, Sanbonmatsu, Powell, and Kardes (1986). In this task, participants were asked to report their evaluation of a variety of attitudinal stimuli that were taken from the Fazio et al. (1986) studies. ${ }^{4}$ Participants were presented a series of 90 words on the computer screen and told that their task was to indicate their evaluation of the object represented by each word by pressing either the good $(J)$ key or the bad $(F)$ key. The objects were randomly presented to each participant. Participants were told to respond as quickly as possible. Our dependent measure was how long participants took to report their evaluation.

Given that participants were expected to slow down when evaluating high-ambivalence rather than low-ambivalence objects (e.g., Bargh et al., 1992), we assessed whether an implemental mind-set would especially facilitate responses to those objects that had the potential to elicit relatively high amounts of ambivalence. Bargh et al. (1992) reported mean ambivalence scores for each object that was determined from a normative study. These scores were based on separate unipolar assessments of positive and negative reactions toward each object, which were combined using a mathematical formula (see Kaplan, 1972); scores could range from 0 (low) to 6 (high). On the basis of this normative data, we categorized those objects that received an ambivalence score below the median ambivalence as "low ambivalence objects" $(M=$ 0.61 ) and those objects that received an ambivalence score above the median ambivalence as "high ambivalence objects" $(M=$ 1.63). Making this distinction, we were able to calculate the mean response latency for objects that had the potential to elicit relatively low or high amounts of ambivalence.

\section{Results}

\section{Content of Manipulation}

We found that $14.6 \%$ of participants' activities, problems, and projects dealt with career-related issues (e.g., studying for a class, publishing a novel, deciding whether to transfer to a different school), 60.2\% dealt with lifestyle-related related issues (e.g., playing video games, preparing a presentation to a group, deciding whether to quit a sports team), and $25.1 \%$ dealt with interpersonal issues (e.g., instant messaging with a friend, planning a wedding, deciding whether to move in with a good friend).

\section{Equivalence of Groups}

In order to check whether our experimental groups differed in their valence of evaluations, for each participant we coded their good evaluations as 1 and their bad evaluations as 0 and created two evaluation indices by averaging across the low- and highambivalence objects. Participants' mean attitude toward low- and high-ambivalence objects was analyzed using a 3 (mind-set condition: implemental, deliberative, neutral) $\times 2$ (potential ambivalence elicited by object: low vs. high) repeated-measures ANOVA, with the first variable as a between-participant variable and the last variable as a within-participant variable. Replicating the positive correlation for ambivalence and valence reported by Bargh et al. (1992, p. 898), our results revealed a significant main effect of ambivalence, $F(1,93)=1,159.77, p<.001$, with highambivalence objects evaluated more positively $(M=.64, S D=$ $.08)$ than low-ambivalence objects $(M=.39, S D=.05)$. Although the main effect of mind-set condition was not significant, $F(2$, $93)=1.86, p=.16$, the Ambivalence $\times$ Condition interaction was significant, $F(2,93)=4.04, p<.05$.

Although the simple effects of mind-set condition for the lowambivalence objects were not significant $(F<1)$, the simple effects of condition for the high-ambivalence objects were significant, $F(2,93)=3.42, p<.05$. Specific comparisons showed that the implemental mind-set group evaluated high-ambivalence objects less positively than the neutral $(M=.61, S D=.08$ vs. $M=$ $.65, S D=.09), t(62)=2.13, p<.05, d=0.54$, and deliberative

\footnotetext{
${ }^{4}$ Note that the Fazio, Sanbonmatsu, Powell, and Kardes (1986) and Bargh et al. (1992) studies had 92 attitude objects. In the current experiment, we presented participants with 90 of them. We omitted Reagan and Russia because the normative data was collected during 1980s, and we felt the historical meaning of these objects has considerably changed.
} 
$(M=.65, S D=.07, t(62)=2.41, p<.05, d=0.61$, mind-set groups. No difference was observed $(t<1)$ between the deliberative and neutral mind-set groups.

\section{Attitude Accessibility}

In order to ensure that our results were not due to any semantic relationship between the objects and participants' goal decisions, we took the following steps before analyzing response times. For every participant in the deliberative mind-set group we identified all objects $(.01 \%)$ that were semantically related to their problem, and for every participant in the implemental mind-set group we identified all objects $(.05 \%)$ that were semantically related to their project. We then deleted response times for these objects before creating an overall index of response time. As recommended by Bargh and Chartrand (2000), several additional steps were taken before analyzing the response time data. To reduce the influence of outlier response latencies on the analyses, a response was excluded from the analyses if it was less than $300 \mathrm{~ms}(.005 \%)$ or greater than 2.5 standard deviations $(.06 \%)$ from the mean response latency. Statistical analyses were performed on log-transformed data, but nontransformed response times are reported here. Finally, for each participant we calculated the mean response time for good and bad responses for low- and high-ambivalence objects.

We conducted a 3 (mind-set condition: deliberative vs. implemental vs. neutral) $\times 2$ (potential ambivalence elicited by object: low vs. high) $\times 2$ (evaluation: good vs. bad) repeated-measures ANOVA on these response times. Replicating the results from Bargh et al. (1992, p. 897), analyses revealed a significant main effect of ambivalence, $F(1,93)=49.86, p<.001$, with participants taking longer to respond to objects that had the potential to elicit high $(M=862 \mathrm{~ms}, S D=204)$ rather than low $(M=827 \mathrm{~ms}$, $S D=186)$ ambivalence. In addition, a significant main effect of condition, $F(2,93)=3.54, p<.05$, emerged. Specific comparisons showed, as expected, that the implemental mind-set group evidenced significantly faster response times $(M=786 \mathrm{~ms}, S D=$ 205) compared with the neutral $(M=869 \mathrm{~ms}, S D=176), t(62)=$ $2.07, p<.05, d=0.53$, and deliberative $(M=877 \mathrm{~ms}, S D=182)$, $t(62)=2.25, p<.05, d=0.57$, mind-set groups. No significant difference was observed $(t<1)$ between the deliberative and neutral mind-set groups.

Also, as expected, the main effects of object ambivalence and condition were qualified by an Ambivalence $\times$ Condition interaction effect, $F(2,93)=2.94, p=.06$. Analysis of the simple effects of condition for the low-ambivalence objects revealed a marginal effect of mind-set condition, $F(2,93)=2.70, p=.07$. Specific comparisons revealed a marginal difference between the implemental and neutral mind-set groups $(M=777 \mathrm{~ms}, S D=203$ vs. $M=844 \mathrm{~ms}, S D=177), t(62)=1.71, p=.09, d=0.43$, and a significant difference between the implemental and deliberative mind-set groups $(M=859 \mathrm{~ms}, S D=171), t(62)=2.11, p<.05$, $d=0.54$. No significant difference was observed $(t<1)$ between the deliberative and neutral mind-set groups. As expected, analysis of the simple effects of condition for the high-ambivalence objects revealed a significant effect of condition, $F(2,93)=3.72, p<.05$. Specific comparisons showed that the implemental mind-set group was faster than the neutral $(M=796 \mathrm{~ms}, S D=214$ vs. $M=895$, $S D=189), t(62)=2.26, p<.05, d=0.57$, and deliberative $(M$ $=896 \mathrm{~ms}, S D=200), t(62)=2.29, p<.05, d=0.58$, mind-set groups. Again, no difference was observed $(t<1)$ between the deliberative and neutral mind-set groups. It is important to note that neither the Condition $\times$ Evaluation interaction effect, $F(2$, 93) $=2.19, p=.12$, nor the Condition $\times$ Evaluation $\times$ Ambivalence effect $(F<1)$ was significant.

In addition to the above analyses, we conducted paired-samples $t$ tests for response times for high- and low-ambivalence objects for our three experimental conditions. Results revealed that both the deliberative ( $M=896 \mathrm{~ms}$ vs. $M=859 \mathrm{~ms}), t(31)=2.75, p=$ $.01, d=0.99$, and neutral $(M=895 \mathrm{~ms}$ vs. $M=844 \mathrm{~ms}), t(31)=$ 2.93, $p<.01, d=1.05$, mind-set groups showed a significant increase in response time when evaluating high- versus lowambivalence objects. In contrast, the implemental mind-set group showed only a marginal ambivalence effect, as they responded quickly no matter whether high- versus low-ambivalence objects had to be evaluated ( $M=796 \mathrm{~ms}$ vs. $M=777 \mathrm{~ms}), t(31)=1.82$, $p=.08, d=0.655^{5}$

\section{Discussion}

In this experiment, we found that individuals induced into an implemental mind-set evidenced faster evaluative responding as compared to individuals induced into either a deliberative or neutral mind-set. This is consistent with prior work that found an implemental mind-set facilitated faster behavioral judgments (see Pösl, 1994, as cited in Gollwitzer \& Bayer, 1999). Note that the increased accessibility demonstrated by the implemental mind-set group seemed to be more pronounced when they evaluated objects that were known to elicit relatively high amounts of ambivalence. This enhanced effect of an implemental mind-set for objects that had the potential to elicit weak (ambivalent) attitudes supports our claim that an implemental mind-set increases the strength associated with people's attitudes. This seems especially relevant to Bargh et al.'s (1992, p. 896) comment that the act of suppressing competing dominant and nondominant responses toward objects requires attentional resources. The results of the current experiment suggest that the act of suppressing such competing evaluative responses may be quite easy while in an implemental mind-set.

\section{Experiment 4: Does an Implemental Mind-Set Improve Attitude-Behavior Correspondence?}

In our first three experiments, we used a variety of approaches to examine the impact of an implemental mind-set on attitude strength, including measures of extremity, ambivalence, and accessibility. Regardless of which method was used, our results

\footnotetext{
${ }^{5}$ The following section presents results that were outside the scope of our hypotheses. Replicating the results from Bargh et al. (1992, p. 897), analyses revealed a significant main effect of evaluation, $F(1,93)=69.10$, $p<.001$, with participants taking longer to report bad $(M=874 \mathrm{~ms}, S D=$ 200) rather than good evaluations $(M=820 \mathrm{~ms}, S D=192)$. These main effects were qualified by a significant interaction effect between ambivalence and evaluation, $F(1,93)=21.67, p<.001$. Paired samples t-tests revealed that the difference in response time for high- versus lowambivalence objects was more pronounced for bad $(M=932 \mathrm{~ms}, S D=$ 241 vs. $M=842 \mathrm{~ms}, S D=186), t(95)=8.73, p<.001, d=1.79$, rather than good evaluations $(M=828 \mathrm{~ms}, S D=199$ vs. $M=807 \mathrm{~ms}, S D=$ 202), $t(95)=2.39, p<.05, d=0.49$.
} 
indicate that the activation of an implemental mind-set led to increased attitude strength toward objects that were unrelated to the decision that triggered the mind-set. The repeated failure to observe any effect of a deliberative mind-set as compared to a neutral mind-set seems to suggest that the main impact of selfregulatory mind-sets on the examined aspects of attitude strength derives from the evaluative focus activated by the postdecisional planning mode of goal pursuit. Given that a deliberative mind-set has failed to show any effects on attitude strength thus far, this experiment exclusively examines the effects of an implemental mind-set relative to a neutral mind-set. Specifically, we examine whether the effects of an implemental mind-set on the evaluative system are substantive enough to increase the predictive power of attitudes for behavior. Indeed, one of the hallmark indicators of attitude strength is an increased correspondence between attitudes and relevant behavior (see Petty \& Krosnick, 1995).

Theorists (e.g., Brehm, 1956; Wicklund \& Brehm, 1976) have long suggested that when action must be maintained toward an object, individuals naturally focus on their dominant evaluative reaction toward the object, exhibiting what some have labeled as an "unequivocal action orientation" (Jones \& Gerard, 1967; see also Gerard, 1992; Harmon-Jones \& Harmon-Jones, 2002). For example, White and Gerard (1981) found that the more immediate the transaction with a chosen alternative, the greater the tendency to enhance one's evaluation of the chosen alternative over the nonchosen alternative; when action was extremely delayed, no such evaluative spreading of alternatives occurred. In essence, when action must be carried out, individuals seem to naturally drown out any extraneous evaluative input from nondominant tendencies that might cloud their commitment by placing extra emphasis on their dominant evaluations.

We assume that when individuals consider objects while in an implemental mind-set, they respond toward objects as if action must be carried out toward them. Accordingly, when individuals report their attitude toward objects while in an implemental mindset, they are likely to provide an attitude that has less-extraneous evaluative variables associated with it (i.e., an attitude based on an evaluatively one-sided focus). Consequently, we hypothesized that when individuals eventually engage in action toward an object, the attitude that is reported while in an implemental mind-set should serve as a better predictor of how they act. It is important to reiterate that we predicted that this effect would occur even though action is called for after the implemental mind-set is no longer active. The fact that action is called for should naturally lead people to narrow their focus on their dominant evaluative reactions (White \& Gerard, 1981), making the behavior more in line with the attitude that was initially reported while in an implemental mindset.

\section{Method}

\section{Participants}

Participants were 116 students (92 women, 24 men) enrolled in one of several psychology courses who participated in partial fulfillment of a course requirement. The procedure for recruiting participants and collecting data was the same as that used in Experiment 2 with the following additions.

\section{Procedure and Materials}

This experiment was longitudinal with data collected at two time points separated by at least 7 days. At the first time point, participants were induced into either an implemental or neutral mind-set prior to responding to a question that accessed their attitude toward the focal object-low-fat dieting. Seven days after participants sent their responses to the experimenter via e-mail, we sent participants two follow-up questions via e-mail that assessed their eating behavior over the past week.

Out of the 116 who completed the attitude assessment at Time 1, 104 completed the behavior assessment at Time 2 (90\% response rate). There were no significant differences between those participants who did and those who did not respond to the behavior assessment in attitude, $t(114)=1.30, p=.20$. Also, there was no significant difference $(t<1)$ between the implemental and neutral mind-set groups in the number of hours it took them to respond to the follow-up questions.

Mind-set manipulation. Disguised as a questionnaire about the type of activities that people engage in, the same procedures used in Experiment 3 to assign participants to the implemental or neutral mind-set conditions were used in the current experiment.

Dependent measures. After participants completed the mindset manipulation, they encountered a statement informing them that the experimenter was interested in their attitude toward a certain object: dieting. Participants' attitude toward eating a lowfat diet was then measured by means of the following 7-point rating scale: "Eating a low-fat diet in the future is ...?" The answer scale ranged from -3 (unpleasant) to 3 (pleasant). After the attitude assessment, participants answered demographic questions. After participants completed the computer program, an electronic file containing the participants' responses was automatically created and saved onto their desktop. Participants were instructed to send this response file to the experimenter via e-mail. Seven days after the experimenter received participants' response files, participants were contacted via e-mail and asked two questions about their eating behavior over the past week. Specifically, participants' eating behavior was measured by means of the following 7-point rating scales: "I have eaten a low-fat diet in the last week," with responses ranged from -3 (strongly disagree) to 3 (strongly agree), and "How often did you eat a low-fat diet in the last week?," with responses ranged from -3 (never) to 3 (frequently). We created an index of low-fat eating behavior by averaging participants' responses to these two items $(r=.93)$. We adopted our attitude and behavior measures from Armitage and Conner's (2000) studies.

\section{Results}

\section{Content of Manipulation}

We found that $39.4 \%$ of participants' activities and projects dealt with career-related issues (e.g., attending class, securing a good score on a standardized test), $42.6 \%$ dealt with lifestylerelated issues (e.g. drinking coffee, finding an affordable apartment), and $18.0 \%$ dealt with interpersonal issues (e.g., talking to friends on the phone, getting a significant other to be more expressive). Nine participants in the implemental mind-set condition planned out a personal project that dealt with eating a healthy diet and were thus dropped from the analysis. Thus, we were left with 
a sample of 95 participants ( 75 women, 20 men), with 49 and 46 participants in the neutral and implemental mind-set conditions, respectively.

\section{Main Analyses}

We examined the relationship between participants' attitude toward eating a low-fat diet and their behavior toward eating a low-fat diet. Participants' gender did not moderate the condition effect for any of the results reported, and all results are unchanged after controlling for the effect of participants' gender; thus, gender is not discussed further. As expected, the within-condition correlations revealed that the implemental mind-set group evidenced a higher correlation $(r=.54)$ than the neutral mind-set group $(r=$ $.22)$ on their attitude toward eating a low-fat diet and their selfreported behavior of eating a low-fat diet $(Z=1.79, p=.06){ }^{6}$

\section{Discussion}

An implemental mind-set is posited to increase the strength associated with people's attitudes, and several studies have shown that changes in attitudinal strength properties can lead to better attitude-behavior relations, including decreases in ambivalence (Armitage \& Conner, 2000) and increases in certainty (Fazio \& Zanna, 1978), accessibility (Fazio, Powell, \& Williams, 1989), and extremity (Petersen \& Dutton, 1975). The observed increase in attitude-behavior correspondence that occurred as a function of an implemental mind-set is consistent with prior research that has shown that postdecisional individuals exhibit an unequivocal behavioral orientation (Jones \& Gerard, 1967). What is novel about the current findings, however, is that such an orientation (once activated) seems to be able to spill over to unrelated objects. Although the findings from this experiment suggest that the increase in attitude strength that occurs as a function of an implemental mind-set is meaningful enough to enhance the predictability of people's attitudes for their behavior, the question still remains as to how exactly an implemental mind-set affects the strength associated with people's attitudes.

\section{Experiment 5: How Does an Implemental Mind-Set Affect Attitude Strength?}

Throughout the previous studies, we have assumed that the mechanism behind an implemental mind-set's affect on attitude strength is the one-sided analysis of information that occurs after a decision is made. Of course, it is also possible that simply making a decision is sufficient to foster increased attitude strength in general, without necessitating a one-sided focus as the driving mechanism. Prior mind-set work has never teased apart the act of deciding and the one- versus two-sided focus. This might not be surprising, however, given that individuals in a postdecisional state generally spontaneously tune their thoughts in a one-sided manner (Taylor \& Gollwitzer, 1995). Nevertheless, it is worthwhile to pinpoint the exact mechanism underlying the effect an implemental mind-set has on attitude strength. The current experiment set out to examine this mechanism, with ambivalence and certainty as the focal aspects of attitude strength to test our hypothesis.

\section{Method}

\section{Participants}

Participants were 46 former and current students ( 25 women, 21 men) recruited via several University of Chicago electronic postings (newsgroup site, Facebook, and listserve notification) who participated for $\$ 10$. The procedure for collecting data was the same as that used in Experiments 2 and 4 with the following additions.

\section{Procedure and Materials}

After receiving the instructions over e-mail, participants were instructed to respond to the study when no other people were around in order to minimize distractions. Participants were randomly assigned to one of three conditions: implemental mind-set one-sided focus, implemental mind-set two-sided focus, or neutral mind-set. There were 15 participants in each of the implemental mind-set conditions and 16 participants in the neutral mind-set condition.

Mind-set manipulation. The procedure used in Experiment 1 to activate an implemental mind-set was applied in the current experiment. For participants assigned to the implemental mindset one-sided focus condition, after they read the sample letter they listed three reasons why it could be desirable and easy to give advice on their chosen romantic area. Note that this onesided evaluative focus resembles the type of biased processing that has been shown to naturally occur once people enter into the postdecisional phase of goal pursuit (e.g. Taylor \& Gollwitzer, 1995). For participants assigned to the implemental mind-set two-sided focus condition, after they read the sample letter they listed three reasons why it could be desirable and easy to give advice on their chosen area and three reasons why it could be undesirable and difficult to give advice on their chosen area. After listing their reasons, participants in the implemental mind-set conditions responded to the attitude questionnaire. The procedures used in Experiments 3 and 4 to activate a neutral mind-set were applied in the current

\footnotetext{
${ }^{6}$ It is worth noting that we also measured the amount of time participants took to report their attitude in Experiment 4. It is interesting that, as was found in Experiment 3, results revealed that the implemental mind-set group took significantly less time $(M=7.04 \mathrm{~s}, S D=2.49)$ than the neutral mind-set group $(M=8.25 \mathrm{~s}, S D=2.95), t(93)=2.16, p<.05, d=0.45$, to report their attitude. We created an index of attitude-behavior correspondence (the absolute distance between the ratings on the attitude and behavior scales). Analyses showed that the correlation between response time and correspondence was practically zero in both the implemental $(r=$ $-.08)$ and neutral $(r=.01)$ mind-set groups, suggesting that the observed difference in accessibility did not mediate the effect of the implemental mind-set on correspondence. It should be noted, however, that participants were not instructed to respond as quickly as possible when reporting their evaluation, as has been done in prior accessibility and attitude-behavior correspondence studies (e.g., Fazio et al., 1989).
} 
experiment. ${ }^{7}$ After participants in the neutral mind-set condition described seven things that they normally did during a typical day, they responded to the attitude questionnaire.

Dependent measure. At the beginning of the attitude questionnaire, participants were asked to indicate their reaction toward a topic that was supposedly being debated within the United States - whether the list of convicted sex offenders should be made available to the general public rather than just the police. Specifically, participants read the following:

Should the list of convicted sex offenders be made available to the general public rather than just the police? On the one hand, people believe that making the registered sex offender list known to the general public rather than just the police would help citizens decide on where they want to live and where to keep children from playing unsupervised, thereby lowering the incident of future offenses. On the other hand, people believe that making the registered sex offender list known to the general public rather than just the police would make it so difficult for offenders to find a place to live and work that it would lead offenders to avoid registering as a sex offender in the first place, thereby increasing the incident of future offenses.

In order to reduce the likelihood that participants already held a strong attitude toward this issue, we excluded 1 participant from the analyses who reported having direct contact with a sex offender in her neighborhood.

We assessed how ambivalent people were toward the issue using the following 7-point rating scales: "I have strong mixed emotions both for and against making the list of convicted sex offenders available to the general public rather than just the police" (reverse scored) and "I do not find myself feeling torn between the two sides of the issue of making the list of convicted sex offenders available to the general public rather than just the police," on scales ranged from -3 (strongly disagree) to 3 (strongly agree). Participants were also asked "To what extent are you indecisive when it comes to making the list of convicted sex offenders available to the general public rather than just the police?" That scale ranged from 1 (not at all) to 7 (very much). These items were adopted from previous ambivalence studies (Newby-Clark, McGregor, \& Zanna, 2001; Priester \& Petty, 1996). After recoding the scale for the last item to range from -3 to 3 , we created an index of ambivalence by averaging responses to the three items $(\alpha=.93)$. We also assessed how certain people were about their attitude toward the issue using the following 7-point rating scale: "How certain are you about your attitude toward making the list of convicted sex offenders available to the general public rather than just the police?" The scale ranged from 1 (not at all) to 7 (very much). As expected, certainty scores were significantly negatively correlated with ambivalence scores $(r=-.69)$. Finally, participants' demographics were assessed.

\section{Results}

\section{Attitude Ambivalence}

Participants' ambivalence score was entered into an ANOVA, with mind-set condition (implemental one-sided, implemental two-sided, and neutral) as a between-participant variable. As expected, the condition effect was significant, $F(2,43)=3.36, p<.05$. Specific comparisons revealed that the implemental mind-set one-sided group evidenced a significantly lower amount of ambivalence $(M=0.16$, $S D=1.85$ ) compared to the implemental mind-set two-sided group
$(M=1.82, S D=1.86), t(28)=2.46, p<.05, d=0.93$. Participants assigned to the neutral mind-set condition scored in the middle $(M=$ $1.23, S D=1.64$ ), although neither significantly above those in the implemental mind-set one-sided condition, $t(28)=1.71, p=.10, d=$ 0.64 , nor significantly below those in the implemental mind-set twosided condition $(t<1)$.

\section{Attitude Certainty}

Participants' certainty score was entered into an ANOVA, with mind-set condition as a between-participant variable. The condition effect was significant, $F(2,43)=4.90, p<.05$ (see Figure 1 ). Specific comparisons revealed that the implemental mind-set onesided group evidenced a significantly higher level of certainty $(M$ $=5.73, S D=1.53)$ than the implemental mind-set two-sided $(M$ $=4.07, S D=1.58), t(28)=2.93, p<.01, d=1.11$, and neutral mind-set $(M=4.25, S D=1.69), t(29)=2.55, p<.05, d=0.95$, groups. No significant difference was observed between the implemental mind-set two-sided and neutral mind-set groups $(t<1){ }^{8}$

\section{Discussion}

Throughout the current set of studies, we have assumed that the mechanism behind an implemental mind-set's effect on attitude strength is the one-sided analysis of information that occurs after a decision is made rather than the simple act of deciding itself. In Experiment 5, we tested our assumption by taking two groups who made a decision on how to act and varying their evaluative focus. Whereas one group engaged in a one-sided evaluation of their decision, the other group engaged in a two-sided evaluation of their decision. Had the act of deciding itself been sufficient to increase attitude strength overall, those individuals who made a decision on how to act and who analyzed both sides of their decision would have evidenced the same level of attitude strength as those who analyzed only one side of their decision. Critically, the findings showed that it was the evaluatively one-sided analysis

\footnotetext{
${ }^{7}$ Results revealed that the implemental one-sided and two-sided groups did not significantly differ in the extent to which they believed they were reading about a particular content area in their sample letter. Specifically, 67\% of participants in one- and two-sided groups choose the honesty area to give advice on and expected to receive a sample letter from that supposed area.

${ }^{8}$ We tested whether participants' level of certainty mediated the effects of mind-set condition on ambivalence by performing a multiple regression analysis testing the linear effect of condition (two-sided group coded -1 , neutral group coded 0 , one-sided group coded 1) and quadratic effect of condition (two-sided and one-sided groups coded -1 , neutral group coded 2). Results revealed that the linear effect of condition on ambivalence was significant, $B=$ $-0.36, t(43)=2.56, p=.01$, and the quadratic effect was not significant $(B=$ $0.06, t<1)$. When we reran the analysis controlling for certainty, the linear effect was no longer significant $(B=-0.11, t<1)$, but the effect of certainty was significant, $B=-0.66, t(42)=5.35, p<.001$. We also tested whether participants' level of ambivalence mediated the effects of mind-set condition on certainty. Results revealed that the linear effect of condition on certainty was significant, $B=0.39, t(43)=2.84, p<.01$, and the quadratic effect was not significant, $B=-0.18, t(43)=1.31, p=.20$. When we reran the analysis controlling for ambivalence, the linear effect was no longer significant, $B=$ $0.17, t(42)=1.45, p=.15$, but the effect of ambivalence was significant, $B=$ $-0.62, t(42)=5.35, p<.001$. Such results can be attributed to the high degree of multicollinearity between ambivalence and certainty.
} 


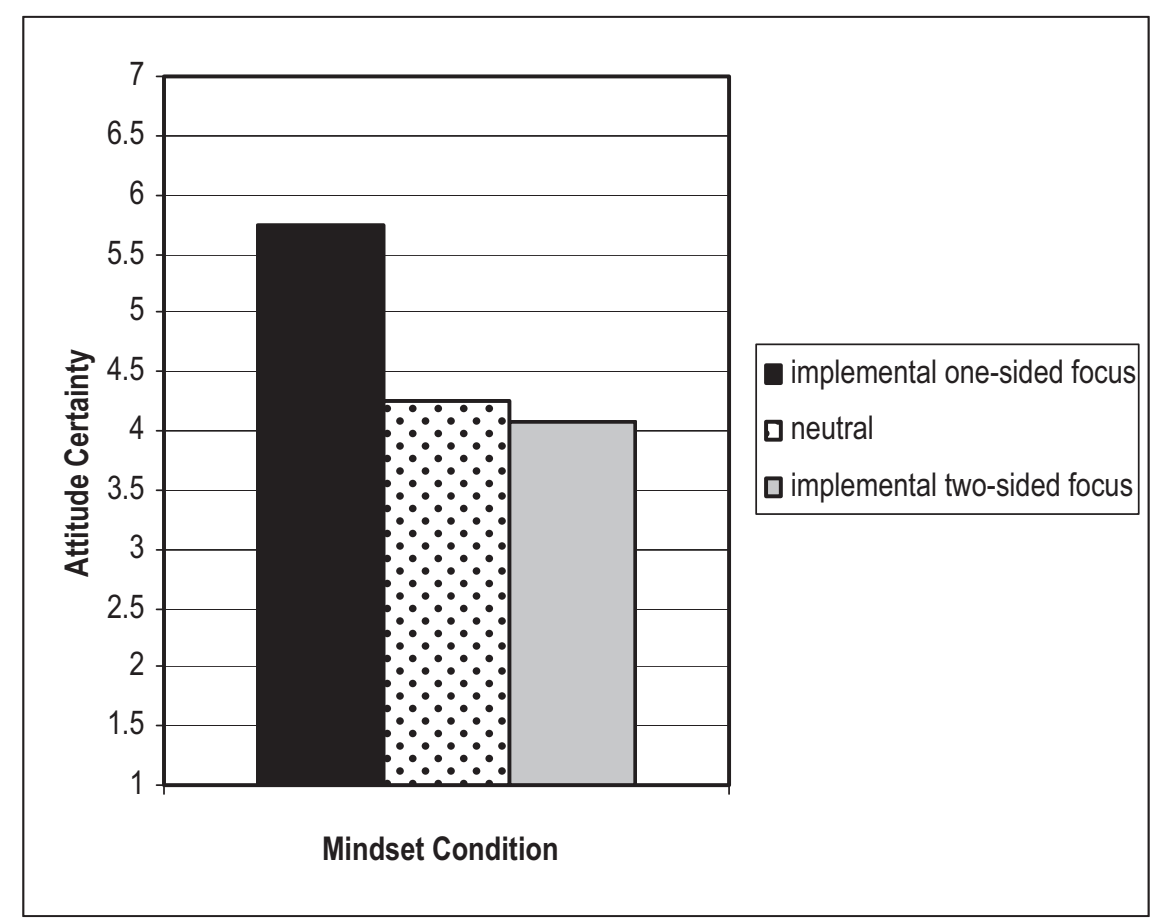

Figure 1. Mean attitude certainty as a function of mind-set (implemental one-sided focus, neutral, and implemental two-sided focus; Experiment 5).

of information, rather than simply the act of deciding itself, that fostered a spillover of decreased ambivalence and increased certainty overall.

\section{General Discussion}

Across the current set of studies, we observed that an implemental mind-set enhances the strength associated with people's attitudes. Such enhanced attitude strength was reflected by an increase in attitudinal extremity (Experiment 1), decrease in attitudinal ambivalence (Experiments 2 and 5), increase in attitudinal accessibility (Experiments 3), increase in attitudinal certainty (Experiments 5), and an increase in attitude-behavior correspondence (Experiment 4). It is important to note that what makes these results particularly striking is the fact that the cognitive approach adopted by individuals in an implemental phase of action was found to transfer or spill over to issues that were completely unrelated to their particular goal pursuits, reflecting a general increase in attitude strength. Of course, one might ask what mechanisms are involved in this general increase in attitude strength that occurs as a function of an implemental mind-set.

An implemental mind-set presumably makes any knowledge that helps to solve the task of the postdecisional phase of goal pursuit more accessible (Gollwitzer, 1990). Part of this knowledge is episodic and relates to information about the specific problem at hand (i.e., the decision to be carried out). The other part includes procedures that help individuals plan and initiate action in general, procedures that involve processing information in an evaluatively one-sided or partial manner. It is this evaluatively one-sided approach that postdecisional individuals naturally take toward goalrelevant information, thus achieving stronger attitudes (increased commitment and reduced uncertainty) toward their goal pursuits. Findings from our last experiment suggest that it is this evaluatively one-sided analysis that produces stronger attitudes toward issues in general, that is, even toward issues that are not linked to the goal pursuit at hand.

\section{Mind-Set Differences}

At this point, one might be wondering why we repeatedly found no differences between our deliberative and neutral mind-set groups on any of our indicators of attitude strength. One might predict that if an implemental mind-set transfers an increase in attitude strength, then a deliberative mind-set must transfer a decrease in attitude strength, given that it precedes the activation of an implemental mind-set in the phases of goal pursuit. As mentioned at the beginning of this article, however, such a prediction rests on the assumption that a neutral mind-set can be created in the first place (see Armor \& Taylor, 2003, p. 89; also see Campbell \& Stanley, 1963, p. 13). For instance, Gagné and Lydon (2001b, p. 1151) suggested that a lack of difference between a deliberative and neutral mind-set group might simply be explained by the generalized state of uncertainty experienced by university students while taking part in psychological experiments, which might be particularly the case when dealing with attitude issues (e.g., policies toward foreigners, policies toward sex offenders) that students are probably unfamiliar with and have not spent much time thinking about beforehand.

Notwithstanding the possible explanation stated above, it is also important to draw attention to the fact that while some studies in the tradition of mind-set theory have found no differences between deliberative and neutral mind-set groups (Brandstätter \& Frank, 
2002, Study 1; Gagné \& Lydon, 2001a, Study 3; 2001b, Study 2; Harmon-Jones \& Harmon-Jones, 2002, Study 2; Taylor \& Gollwitzer, 1995, Studies 1 and 2), other studies have found no differences between implemental and neutral mind-set groups (Fujita et al., 2007, Study 3; Gollwitzer \& Kinney, 1989, Study 2; Heckhausen \& Gollwitzer, 1987, Study 2; Taylor \& Gollwitzer, 1995, Study 1). Moreover, other studies have found theoretically consistent differences between all three mind-set groups (Armor \& Taylor, 2003, Preliminary Study; Gagné \& Lydon, 2001b, Study 1; Taylor \& Gollwitzer, 1995, Study 2). Such inconsistent findings might also be due to the existence of an unexplored individual difference in chronic preferences for deliberative versus implemental mind-sets. Indeed, recent work by Grant, Gollwitzer, and Oettingen (2006) supports this possibility, and we look forward to additional work that directly tests this idea.

\section{Alternative Mechanisms}

One might question whether elevations in mood might account for the differences we found between the different mind-set conditions. To us, this explanation seems unlikely given that if the activation of an implemental mind-set did indeed facilitate a better mood, then one would have expected to find that attitudes expressed in the current set of experiments were consistently more positive, something we failed to observe (see Experiments 1 and 4). Moreover, any differences in mood or attitude valence could not account for the differences in attitudinal certainty that we observed (see Experiment 5). Second, one might ask whether our results can be explained by differences in the amount of cognitive effort expended by the groups. This explanation also seems unlikely given that we failed to find any differences between our experimental groups in stimulus recall or effort that went into responding (see Experiment 1). Last, one might wonder whether our results can be accounted for by differences in the topics our experimental groups thought about before responding to our dependent measures. We believe that the results of Experiments 1 and 5 effectively speak against this alternative explanation, specifically because our experimental groups were exposed to the same information (romantic relationship advice materials) before evidencing differences in attitude strength. Moreover, several steps were taken across Experiments 2 to 4 to omit all responses from the analyses that shared any semantic relationship to the content of what our experimental groups thought about beforehand, and a consistent pattern of results still emerged. Therefore, a content explanation also does not seem tenable.

\section{Mind-Sets and Attitude-Behavior Relations}

It is interesting to consider whether an implemental mind-set will always lead to attitudes that predict behavior better, particularly in light of the work by Miller and Tesser (1992) on the mismatch model of attitudes and behavior. Miller and Tesser have argued that attitudes based on cognition are better predictors of instrumental behaviors (behaviors engaged in for distal goals), whereas attitudes based on affect are better predictors of consummatory behaviors (behaviors engaged in for their own sake, enjoyment, or interest value). Throughout the current article, we have remained agnostic as to whether the one-sided focus that occurs as a function of an implemental mind-set is one that is primarily cognitive or affective. Regarding our demonstration of increased attitude-behavior correspondence that occurred as a function of an implemental mind-set, one could argue that the behavior that we measured (dieting) is one that has both consummatory (appetitive concerns) and instrumental (health concerns) aspects, and therefore it is difficult to draw any clear conclusions from the current findings about whether an implemental mind-set differentially affects the correspondence between attitudes and behaviors that are consummatory or instrumental in nature. Indeed, Tesser and Martin have noted (e.g., Tesser, Martin, \& Mendolia, 1995) the difficulty in identifying behavior as clearly consummatory or instrumental. We believe future research should specifically tackle this issue by examining the specific type of focus (cognitive or affective) that occurs as a function of an implemental mind-set and by using paradigms that make explicit the nature of the behavior (e.g., see Miller \& Tessar, 1986). ${ }^{9}$

\section{Mind-Sets and Attitude Strength}

The current experiments focused on whether an implemental mind-set increases the strength associated with particular aspects of attitudes identified by Pomerantz and her colleagues (Pomerantz et al., 1995; Tordesillas et al., 1994) as having to do with the confidence people have in their attitudes. Future work should examine whether an implemental mind-set also affects the consequences of such increased attitude strength, including an attitude's persistence over time and resistance to change. It is important to recognize that Pomerantz and her colleagues also found that certain aspects of attitude strength (ego involvement, importance, knowledgeability) centered on how connected individuals' attitudes were to their values and belief system. They found that increases on such properties of attitude strength were associated with what they referred to as an "open-minded orientation" toward attitude-incongruent information (Pomerantz et al., 1995, pp. 416417). Pomerantz and her colleague's identification of aspects of attitude strength that are related to individuals' values and associated with an open-minded orientation fit well with the deliberative mind-set (Gollwitzer, 1990; 2003). As the deliberative mind-set has been shown to reflect an open-minded consideration of available information (Fujita et al., 2007; Heckhausen \& Gollwitzer, 1987), it undoubtedly centers on considering one's values and belief system while attempting to narrow down which of the many desires will be pursued. Future research should therefore be directed at testing whether a deliberative mind-set affects valuerelated aspects of attitude strength.

\section{Conclusion}

The present line of research was rooted in the assumption that the evaluative system plays a key role in how individuals navigate through the social world. Mind-set theory proposes that one of the key tasks that individuals must resolve in the postdecisional planning phase of goal pursuit is to maintain strong commitment to their goals. The findings from the present set of experiments illustrate that increased levels of attitude strength will occur as an unintended consequence of solving this task. Together, the results

\footnotetext{
${ }^{9} \mathrm{We}$ are grateful to an anonymous reviewer for raising this issue.
} 
from the current set of experiments offer great theoretical promise for the continued integration of goal pursuit and attitude research.

\section{References}

Abelson, R. P. (1995). Attitude extremity. In R. E. Petty \& J. A. Krosnick (Eds.), Attitude strength: Antecedents and consequences (pp. 25-41). Mahwah, NJ: Erlbaum.

Ach, N. (1910). Über den Willensakt und das Temperament [Temperament and the act of willing]. Leipzig, Germany: Quelle \& Meyer.

Armitage, C. J., \& Conner, M. (2000). Attitudinal ambivalence: A test of three key hypotheses. Personality and Social Psychology Bulletin, 26, $1421-1432$.

Armor, D. A., \& Taylor, S. E. (2003). The effects of mindset on behavior: Self-regulation in deliberative and implemental frames of mind. Personality and Social Psychology Bulletin, 29, 86-95.

Bargh, J. A., Chaiken, S., Govender, R., \& Pratto, F. (1992). The generality of the automatic attitude activation effect. Journal of Personality and Social Psychology, 62, 893-912.

Bargh, J. A., \& Chartrand, T. L. (2000). The mind in the middle: A practical guide to priming and automaticity research. In H. T. Reis \& C. M. Judd (Eds.), Handbook of research methods in social and personality psychology (pp. 253-285). New York: Cambridge University Press.

Bassili, J. N. (1996). Meta-judgmental versus operative indexes of psychological attributes: The case of measures of attitude strength. Journal of Personality and Social Psychology, 71, 637-653.

Bayer, U. C., \& Gollwitzer, P. M. (2005). Mindset effects on information search in self-evaluation. European Journal of Social Psychology, 35, 313-327.

Brandstätter, V., \& Frank, E. (2002). Effects of deliberative and implemental mind-sets on persistence in goal-directed behavior. Personality and Social Psychology Bulletin, 28, 1366-1378.

Brehm, J. W. (1956). Postdecision changes in the desirability of alternatives. Journal of Abnormal and Social Psychology, 52, 384-389.

Brömer, P. (1998). Ambivalent attitudes and information processing. Swiss Journal of Psychology, 57,225-234.

Cacioppo, J. T., von Hippel, W., \& Ernst, J. M. (1997). Mapping cognitive structures and processes through verbal content: The thought-listing technique. Journal of Consulting and Clinical Psychology, 65, 928-940.

Campbell, D. T., \& Stanley, J. C. (1963). Experimental and quasiexperimental designs for research. Boston: Houghton, Mifflin and Company.

Chen, S., Shechter, D., \& Chaiken, S. (1996). Getting at the truth or getting along: Accuracy- vs. impression-motivated heuristic and systematic processing. Journal of Personality and Social Psychology, 71, 262-275.

De Liver, Y., Henderson, M. D., \& Gollwitzer, P. M. (2003). [The effects of self-regulatory mindsets on subjective ambivalence towards goalrelevant objects and events.] Unpublished raw data.

De Liver, Y., Van der Pligt, J., \& Wigboldus, D. (2007). Positive and negative associations underlying ambivalent attitudes. Journal of Experimental Social Psychology, 43, 319-326.

Downing, J. W., Judd, C. M., \& Brauer, M. (1992). Effects of repeated expressions on attitude extremity. Journal of Personality and Social Psychology, 63, 17-29.

Fazio, R. H., Chen, J., McDonel, E. C., \& Sherman, S. J. (1982). Attitude accessibility, attitude-behavior consistency, and the strength of the object-evaluation association. Journal of Experimental Social Psychology, 18, 339-357.

Fazio, R. H., Powell, M. C., \& Williams, C. J. (1989). The role of attitude accessibility in the attitude-to-behavior process. Journal of Consumer Research, 16, 280-288.

Fazio, R. H., Sanbonmatsu, D. M., Powell, M. C., \& Kardes, F. R. (1986). On the automatic activation of attitudes. Journal of Personality and Social Psychology, 50, 229-238.
Fazio, R. H., \& Zanna, M. P. (1978). Attitudinal qualities relating to the strength of the attitude-behavior relationship. Journal of Experimental Social Psychology, 14, 398-408

Frey, D. (1986). Recent research on selective exposure to information. In L. Berkowitz (Ed.), Advances in experimental social psychology (Vol. 19, pp. 41-80). Orlando, FL: Academic Press.

Fujita, K., Gollwitzer, P. M., \& Oettingen, G. (2007). Mindsets and pre-conscious open-mindedness to incidental information. Journal of Experimental Social Psychology, 43, 48-61.

Gagné, F. M., \& Lydon, J. E. (2001a). Mind-set and close relationships: When bias leads to (in)accurate predictions. Journal of Personality and Social Psychology, 81, 85-96.

Gagné, F. M., \& Lydon, J. E. (2001b). Mindset and relationship illusions: The moderating effects of domain specificity and relationship commitment. Personality and Social Psychology Bulletin, 27, 1144-1155.

Galinsky, A. D., \& Moskowitz, G. B. (2000). Counterfactuals as behavioral primes: Priming the simulation heuristic and consideration of alternatives. Journal of Experimental Social Psychology, 36, 384-409.

Gerard, H. B. (1967). Choice difficulty, dissonance and the decision sequence. Journal of Personality, 35, 91-108.

Gerard, H. B. (1992). Dissonance theory: A cognitive psychology with an engine. Psychological Inquiry, 3, 323-327.

Gollwitzer, P. M. (1990). Action phases and mind-sets. In E. T. Higgins \& R. M. Sorrentino (Eds.), Handbook of motivation and cognition: Foundations of social behavior (Vol. 2, pp. 53-92). New York: Guilford Press.

Gollwitzer, P. M. (2003). Why we thought that action mindsets affect illusions of control. Psychological Inquiry, 14, 261-269.

Gollwitzer, P. M., \& Bayer, U. (1999). Deliberative versus implemental mindsets in the control of action. In S. Chaiken \& Y. Trope (Eds.), Dual-process theories in social psychology (pp. 403-422). New York: Guilford Press

Gollwitzer, P. M., Bayer, U., \& Wasel, W. (1998). Deliberative versus implemental mindsets: The issue of openmindedness. Unpublished manuscript, Universität Konstanz, Konstanz, Germany.

Gollwitzer, P. M., Fujita, K., \& Oettingen, G. (2004). Planning and the implementation of goals. In R. F. Baumeister \& K. D. Vohs (Eds.), Handbook of self-regulation: Research, theory, and applications (pp. 211-228). New York: Guilford Press.

Gollwitzer, P. M., Heckhausen, H., \& Steller, B. (1990). Deliberative and implemental mind-sets: Cognitive tuning toward congruous thoughts and information. Journal of Personality and Social Psychology, 59, $1119-1127$.

Gollwitzer, P. M., \& Kinney, R. F. (1989). Effects of deliberative and implemental mind-sets on illusion of control. Journal of Personality and Social Psychology, 56, 531-542.

Grant, H., Gollwitzer, P. M., \& Oettingen, G. (2006). Individual differences in the self-regulation of goal pursuit by forming implementation intentions. Unpublished manuscript, Lehigh University, Bethlehem, PA.

Harmon-Jones, E., \& Harmon-Jones, C. (2002). Testing the action-based model of cognitive dissonance: The effect of action orientation on postdecisional attitudes. Personality and Social Psychology Bulletin, 28, 711-723.

Heckhausen, H., \& Gollwitzer, P. M. (1987). Thought contents and cognitive functioning in motivational versus volitional states of mind. Motivation and Emotion, 11, 101-120.

Higgins, E. T., Kruglanski, A. W., \& Pierro, A. (2003). Regulatory mode: Locomotion and assessment as distinct orientations. In M. P. Zanna (Ed.), Advances in experimental social psychology (Vol. 35, pp. 293 344). New York: Academic Press.

Huckfeldt, R., \& Sprague, J. (2000). Political consequences of inconsistency: The accessibility and stability of abortion attitudes. Political Psychology, 21, 57-79.

Hugenberg, K., Bodenhausen, G. V., \& McLain, M. (2006). Framing 
discrimination: Effects of inclusion versus exclusion mind-sets on stereotypic judgments, Journal of Personality and Social Psychology, 91, $1020-1031$

Jones, E. E., \& Gerard, H. (1967). Foundations of social psychology. Oxford, England: Wiley.

Kaplan, K. J. (1972). On the ambivalence-indifference problem in attitude theory and measurement: A suggested modification of the semantic differential technique. Psychological Review, 77, 361-372.

Kray, L. J., Galinsky, A. D., \& Wong, E. M. (2006). Thinking within the box: The relational processing style elicited by counterfactual mind-sets. Journal of Personality and Social Psychology, 91, 33-48.

Krosnick, J. A. (1988). The role of attitude importance in social evaluation: A study of policy preferences, presidential candidate evaluations, and voting behavior. Journal of Personality and Social Psychology, 55, 196-210.

Krosnick, J. A., Boninger, D. S., Chuang, Y. C., Berent, M. K., \& Carnot, C. G. (1993). Attitude strength: One construct or many related constructs? Journal of Personality and Social Psychology, 65, 1132-1151.

Krosnick, J. A., \& Petty, R. E. (1995). Attitude strength: An overview. In R. E. Petty, \& J. A. Krosnick (Eds.), Attitude strength: Antecedents and consequences: Ohio State University Series on Attitudes and Persuasion (Vol. 4, pp. 1-24). Hillsdale, NJ: Erlbaum.

Kruglanski, A. W., Thompson, E. P., Higgins, E. T., Atash, M. N., Pierro, A., Shah, J. Y., \& Spiegel, S. (2000). To "do the right thing" or to "just do it": Locomotion and assessment as distinct self-regulatory imperatives. Journal of Personality and Social Psychology, 79, 793-815.

Kuhl, J. (1985). Volitional mediation of cognition-behavior consistency: Self-regulatory processes and action versus state orientation. In J. Kuhl \& J. Beckman (Eds.), Action control: From cognition to behavior (pp. 101-128). Berlin, Germany: Springer-Verlag.

Külpe, O. (1904). Versuche über Abstraktion [Experiments on abstraction]. Bericht über den 1. Kongre $\beta$ für Experimentelle Psychologie, 1, 56-68.

Miller, M., \& Tesser, A. (1986). Effects of affective and cognitive focus on the attitude-behavior relationship. Journal of Personality and Social Psychology, 51, 259-269.

Miller, M., \& Tesser, A. (1992). The role of beliefs and feelings in guiding behavior: The mismatch model. In L. Martin \& A. Tesser (Eds.), The construction of social judgments (pp. 277-300). Hillsdale, NJ: Erlbaum.

Newby-Clark, I. R., McGregor, I., \& Zanna, M. P. (2002). Thinking and caring about cognitive inconsistency: When and for whom does attitudinal ambivalence feel uncomfortable? Journal of Personality and Social Psychology, 82, 157-166.

Nordgren, L. F., van Harreveld, F., \& Van der Pligt, J. (2006). Ambivalence, discomfort, and motivated information processing. Journal of Experimental Social Psychology, 42, 252-258.

Petersen, K. K., \& Dutton, J. E. (1975). Centrality, extremity, intensity: Neglected variables in research on attitude-behavior consistency. Social Forces, 54, 393-414.

Petty, R. E., \& Krosnick, J. A. (1995). Attitude strength: Antecedents and consequences: Ohio State University Series on Attitudes and Persuasion (Vol. 4). Hillsdale, NJ: Erlbaum.

Pomerantz, E. M., Chaiken, S., \& Tordesillas, R. S. (1995). Attitude strength and resistance processes. Journal of Personality and Social Psychology, 69, 408-419.

Pösl, I. (1994). Wiederaufnahme unterbrochener Handlungen: Effekte der
Bewusstseinslagen des Abwägens und Planens [Deliberative and implemental mindset effects on the resumption of disrupted activities]. Unpublished master's thesis, University of Munich, Germany.

Priester, J. R., \& Petty, R. E. (1996). The gradual threshold model of ambivalence: Relating the positive and negative bases of attitudes to subjective ambivalence. Journal of Personality and Social Psychology, $71,431-449$

Puca, R. M. (2001). Preferred difficulty and subjective probability in different action phases. Motivation and Emotion, 25, 307-326.

Puca, R. M., \& Schmalt, H.-D. (2001). The influence of the achievement motive on spontaneous thoughts in pre- and postdecisional action phases. Personality \& Social Psychology Bulletin, 27, 302-308.

Raden, D. (1985). Strength related attitude dimensions. Social Psychology Quarterly, 48, 312-330.

Rees, H. J., \& Israel, H. E. (1935). An investigation of the establishment and operation of mental sets. Psychological Monographs, 46, 1-26.

Sassenberg, K., \& Moskowitz, G. B. (2005). Do not stereotype, think different! Overcoming automatic stereotype activation by mindset priming. Journal of Experimental Social Psychology, 41, 506-514.

Sassenberg, K., Moskowitz, G. B., Jacoby, J., \& Hansen, N. (2007). The carry-over effect of competition: The impact of competition on prejudice towards uninvolved outgroups. Journal of Experimental Social Psychology, 43, 529-538.

Smith, E. R., \& Branscombe, N. R. (1987). Procedurally mediated social inferences: The case of category accessibility effects. Journal of Experimental Social Psychology, 23, 361-382.

Taylor, S., \& Gollwitzer, P. M. (1995). Effects of mindset on positive illusions. Journal of Personality and Social Psychology, 69, 213-226.

Tesser, A., Martin, L., \& Mendolia, M. (1995). The impact of thought on attitude extremity and attitude-behavior consistency. In R. E. Petty, \& J. A. Krosnick (Eds.), Attitude strength: Antecedents and consequences: Ohio State University Series on Attitudes and Persuasion (Vol.4, pp. 1-24). Hillsdale, NJ: Erlbaum.

Tordesillas, R. S., Pomerantz, E. M., Chaiken, S., \& Zimmerman, J. (1994). Unpublished data set, New York University, New York.

Tormala, Z. L., \& Petty, R. (2002). What doesn't kill me makes me stronger: The effects of resisting persuasion on attitude certainty. Journal of Personality and Social Psychology, 83, 1298-1313.

Visser, P. S., Bizer, G. Y., \& Krosnick, J. A. (2006). Exploring the latent structure of strength-related attitude attributes. Advances in Experimental Social Psychology, 38, 1-67.

Visser, P. S., Krosnick, J. A., \& Simmons, J. P. (2003). Distinguishing the cognitive and behavioral consequences of attitude and certainty: A new approach to testing the common-factor hypothesis. Journal of Experimental Social Psychology, 39, 118-141.

Visser, P. S., \& Mirabile, R. R. (2004). Attitudes in the social context: The impact of social network composition on individual-level attitude strength. Journal of Personality and Social Psychology, 87, 779-795.

White, G. L., \& Gerard, H. B. (1981). Post-decision evaluation of choice alternatives as a function of valence of alternatives, choice, and expected delay of choice consequences. Journal of Research in Personality, 15, 371-382.

Wicklund, R. A., \& Brehm, J. W. (1976). Perspectives on cognitive dissonance. Hillsdale, NJ: Erlbaum. 


\section{Appendix A}

\section{Stimulus Material Used in Experiments 1 and 5}

\section{Sample Honesty (Sexual Experience) Issue Letter}

Dear Doctor Love,

I met this person on the Internet three months ago and we talk everyday through instant messenger. Things are going great. We talk for hours and we flirt all the time. Plus, we just seem to connect on a really deep level. This person even sent me a picture, but I'm too timid to send mine. I've been lying that my scanner is broken and I am unable to send anything. Plus, I've kind of led this person on to believe that I'm better looking than I really am. I think this person is so hot and I'm sure others would agree. I don't think I'm attractive and the only people who think I am are my family members, so I tend not to believe them. You know how that goes. "You have a great personality!" "Any person would be lucky to be with you!" "I wish I looked like you when I was younger!" I am 18 and I have only dated two other people ever. To be honest, I know I could stand to loose a few pounds. God I want this person to really like me. It's not that I think this person is an uncaring person who only cares about looks. But come on! Aren't looks a major factor in a relationship? We seem compatible on many levels except for that one. Please help!!

Yours truly,

Dishonest Lover (Inexperienced Lover)

\section{Appendix B}

\section{Examples of Coded Responses from Experiment 1}

Code of -1 (one-sided negative position):

I don't think that e-mails between foreigners should be closely watched. Just because another person is from another country, does not automatically make him/her a terrorist. America does not control the world and should not have rights to control other people's private conversations.

Code of 0 (two-sided negative position):

I believe that privacy is more important than a perceived threat. Without any judicial support, such as warrants, I do not feel government agencies should be able to read private emails.
Code of 0 (two-sided positive position):

Just as cops have a right to search a car or a house on grounds of reasonable suspicion, the government should have some right over monitoring foreigners' email, but what is impermissible is to use that power indiscriminately, without reasonable grounds of suspicion, and in ways that may be malicious.

Code of 1 (one-sided positive position):

I believe that, as the world power, we must do everything necessary to protect ourselves. If this includes tapping peoples' phones and reading peoples' private emails, then I would be in favor of it.

\section{Appendix C}

\section{Attitude Objects Used in Experiment 2}

$\begin{array}{lll}\text { airplanes } & \text { exercising } & \text { nurses } \\ \text { bowling } & \text { computer hackers } & \text { recycling } \\ \text { eating fast-food } & \text { studying } & \text { pornography } \\ \text { skim milk } & \text { video games } & \text { chocolate } \\ \text { police officers } & \text { alcohol } & \text { politicians } \\ \text { blind dates } & \text { cellular phones } & \text { cigarettes } \\ \text { homeless people } & \text { condoms } & \text { firemen } \\ \text { clowns } & \text { sales clerks } & \text { sex } \\ \text { lying to your parents } & \text { bicycles } & \text { lawyers } \\ \text { shopping } & \text { gambling } & \end{array}$

